\title{
STUDI PERSEPSI MASYARAKAT DAN KESESUAIAN PERAIRAN KARANG JAHE SEBAGAI OBYEK REKREASI PANTAI DI KABUPATEN REMBANG, JAWA TENGAH
}

Study of Community Perception and Suitability of Karang Jahe Beach Water as Beach Recreation Object in Rembang District, Central Java

\author{
Wirawan Harjanto, Siti Rudiyanti*), Djoko Suprapto \\ Program Studi Manajemen Sumberdaya Perairan, Departemen Sumberdaya Akuatik \\ Fakultas Perikanan dan Ilmu Kelautan, Universitas Diponegoro \\ Jl. Prof. Soedarto, SH, Tembalang, Semarang, Jawa Tengah - 50275, Telp/Fax. +6224 7474698 \\ Email :wirawanharjanto64@gmail.com
}

\begin{abstract}
ABSTRAK
Pantai Karang Jahe merupakan pantai berpasir putih yang terletak di Desa Punjulharjo, Kabupaten Rembang, Jawa Tengah. Pantai yang luasnya 393,93 ha ini mempunyai potensi wisata pantai yang dapat dikembangkan. Tujuan dari penelitian ini adalah Mengetahui persepsi masyarakat terhadap potensi dan perkembangan wisata di Pantai Karang Jahe dan Mengetahui nilai Indeks Kesesuaian Wisata (IKW) Pantai Karang Jahe beserta kategorinya. Penelitian dilakukan pada bulan Desember 2017-Januari 2018. Penelitian ini menggunakan teknik pengolahan data deskriptif dengan menyebar kuisioner kepada 30 responden masyarakat setempat dan 50 responden pengunjung wisata. Teknik sampling menggunakan teknik purposive sampling dan penilaian kuantitatif menggunakan Indeks Kesesuaian Wisata (IKW) di tiga stasiun. Persepsi masyarakat terhadap potensi di kawasan Pantai Karang Jahe sudah tergolong baik dari kondisi fisik sampai jenis kegiatan dapat dikatakan kawasan ini layak untuk dikunjungi. Perkembangan di kawasan Pantai Karang Jahe ini antara lain pertumbuhan jumlah pengunjung dan penambahan fasilitas / sarana dan prasarana. Pengukuran Nilai Indeks Kesesuaian Wisata (IKW) Pantai Karang Jahe diukur di tiga stasiun I, II dan III saat pagi (surut) 100\%, 97,61\% dan 100\% nilai kategori S1, S1 dan S1 (Sangat Sesuai), di stasiun I, II dan III saat sore (pasang) 96,42\%, 96,42\% dan 96,42\% nilai kategori S1, S1 dan S1 (Sangat Sesuai). Hal ini menunjukkan bahwa Pantai Karang Jahe pada pagi dan sore hari tergolong dalam kategori S1 atau sangat sesuai untuk kegiatan wisata pantai.
\end{abstract}

Kata Kunci: Potensi dan Perkembangan Wisata; Indeks Kesesuaian Wisata; Pantai Karang Jahe.

. Karang Jahe Beach is a white sandy beach which is located in the village of Punjulharjo, Rembang, Central Java. The beach that the extent of this potential 393,93 ha of coastal tourism can be developed. The purpose of this research is to know the perception of society against the potential and development of tourism in coastal Karang Jahe and knowing the value of the Index the Suitability of Tourism (IST) Karang Jahe Beach along with the category. The research was conducted in December 2017-January 2018. This research uses descriptive data processing techniques with a spread of 30 respondents to the questionnaire of the local community and visitors tour the 50 respondents. The sampling technique using a purposive sampling technique and quantitative assessment Index using the Suitability of Tourism (IST) at three stations. Public perception against the potential in the coastal area of the Karang Jahe already belongs to the physical condition of both types of activities can be said this area is worth a visit. Developments in the area of the Karang Jahe Beach is the growth of the number of visitors, the addition of facilities/infrastructure and facilities. Measurement of Index value the Suitability of Tourism (IST) Karang Jahe Beach measured at three stations I, II and III when the morning (receding) 100\%, 97,61\% and 100\% value of category S1, S1 and S1 (very appropriate), at the station I, II and III when the afternoon (pairs) 96,42\%, 96,42\% and 96,42\% value category S1, S1 and S1 (very appropriate). This suggests that Karang Jahe Beach in the morning and evening belongs in category S1 or highly suitable for Beach tourism activities.

Keywords: Tourism Potential and Development; Tourism Conformity Index; Karang Jahe Beach; *) penulis penanggungjawab

\section{PENDAHULUAN}

Pariwisata atau turisme adalah perjalanan yang dilakukan untuk rekreasi atau liburan aktivitas tertentu. Seseorang wisatawan adalah orang yang melakukan perjalanan paling tidak sejauh $80 \mathrm{~km}$ dari rumahnya dengan tujuan rekreasi. Kabupaten Rembang merupakan daerah yang berdekatan dengan laut dan mempunyai garis pantai yang lumayan panjang, yaitu sepanjang $63 \mathrm{~km}$. Kabupaten Rembang memiliki potensi yang dapat dikembangkan diantaranya pada bidang perikanan, pertanian, perdagangan, kehutanan, pertambangan dan pariwisata. Salah satu potensi pariwisata 
di Kabupaten Rembang diantaranya terdapat makam tokoh pahlawan R.A Kartini, museum dan wisata sejarah serta wisata pantai. Wisata pantai menjadi objek pariwisata andalan yang berada di Kabupaten Rembang. Pantai Karang Jahe merupakan tempat wisata alam berupa pantai berpasir putih yang terletak di Jalan Rembang-Lasem, Desa Punjulharjo, Kecamatan Rembang, Kabupaten Rembang, Jawa Tengah, Indonesia.Pantai Karang Jahe cukup mudah dijangkau karena aksesnya berada di jalur pantura.

Tujuan dari penelitian ini adalah untuk mengetahui persepsi masyarakat terhadap potensi dan perkembangan wisata di Pantai Karang Jahe serta mengetahui nilai Indeks Kesesuaian Wisata (IKW) Pantai Karang Jahe serta kategorinya.

\section{MATERI DAN METODE}

\section{A. Materi Penelitian}

Materi yang digunakan pada penelitian ini berupa kuisioner yang disebarkan kepada masyarakat setempat dan pengunjung beserta hasil perhitungan nilai Indeks Kesesuaian Wisata (IKW). Pengisian kuisioner yang disebarkan kepada masyarakat setempat dan pengunjung Pantai Karang Jahe sebanyak 80 responden. 30 responden diberikan kepada masyarakat setempat dan 50 responden diberikan kepada pengunjung Pantai Karang Jahe. Parameter kesesuaian wisata pantai di ukur dengan variabel-variabel seperti kedalaman perairan, tipe pantai, lebar pantai, material dasar perairan, kecepatan arus, kemiringan pantai, kecerahan perairan, penutupan lahan pantai, biota berbahaya dan ketersediaan air tawar. Data sekunder berupa data jumlah pengunjung Pantai Karang Jahe selama tahun 2017 dan data monografi desa untuk mengetahui jumlah masyarakat setempat Pantai Karang Jahe serta mengetahui batas-batas Pantai Karang Jahe.

Alat yang dibutuhkan dalam penelitian ini yaitu meliputi alat tulis yang digunakan sebagai alat pencatatan sewaktu dilapangan, kertas yang digunakan sebagai pencatatan data hasil pengamatan dilapangan, secchi disk modifikasi sebagai alat untuk pengukuran nilai kecerahan perairan, kedalaman perairan dan kemiringan pantai, Rollmeter digunakan sebagai alat pengukur nilai kemiringan pantai dan lebar pantai, bola arus sebagai alat mengukur nilai kecepatan arus perairan, GPS berfungsi sebagai penentu koordinat stasiun, kalkulator scientific alat untuk menghitung nilai kemiringan pantai serta menghitung Indeks Kesesuaian Wisata (IKW) dan kuisioner sebagai pengambilan data potensial dan perkembangan Wisata Pantai Karang Jahe.

\section{B. Metode Penelitian}

Metode penelitian ini menggunakan teknik pengolahan data deskriptif dengan menyebar kuisioner kepada 30 responden masyarakat setempat dan 50 responden pengunjung wisata. Teknik sampling menggunakan teknik purposive sampling dan penilaian kuantitatif menggunakan Indeks Kesesuaian Wisata (IKW) di tiga stasiun.

\section{TahapanPenelitian}

Tahapan-tahapan yang dilakukan dalam penelitian ini adalah sebagai berikut:

- Tahapan Persiapan Lapangan

Tahap awal yang dilakukan yaitu dengan cara observasi, hal tersebut dapat mengetahui permasalahan yang berada dilapangan. Tahapan selanjutnya dilakukan studi literatur sebagai penguat kerangka teoritis, perumusan masalah, pengumpulan literatur dan penyusunan kerangka.

- Pengumpulan Data saat di Lapangan

Data yang dibutuhkan adalah data primer dan data sekunder. Data primer yaitu mencari responden sebagai pengisi koesioner, Indeks Kesesuaian Wisata di ukur 10 variabel-variabel yang berada dilapangan. Sedangkan data sekunder yaitu data penguat hasil penelitian dilapangan.

- Analisis Data

Setelah kedua tahap terlaksana tahap terakhir yaitu dengan cara menganalisis data yang sudah didapat menggunakan analisis kesesuaian wisata dan secara deskriptif, kemudian didapatkan kesimpulan Pantai Karang Jahe sesuai atau tidak sesuai untuk dikembangkan menjadi kawasan wisata.

\section{Teknik Pengambilan Data}

Data yang digunakan dalam penelitian ini ada 2 data, yaitu:

1. Data Primer

\section{a. Kuisioner}

Dilihat dari sumber datanya, maka pengumpulan data primer menggunakan teknik purposive sampling. Data primer adalah sumber data yang langsung memberikan data kepada pengumpul data. Data primer merupakan kuesioner yang berisi pernyataan tertutup. Menggunakan metode semantic deferensial, dengan skor 1 sampai 5 dimana skor 5 menggambarkan "Sangat Setuju" sedangkan skor 1 menggambarkan "Sangat Tidak Setuju". Teknik pengumpulan data yang digunakan oleh peneliti adalah menggunakan kuisioner (angket) yang berisikan pernyataan. (Sugiyono, 2007).

Purposive sampling yaitu pengambilan sampel berdasarkan penilaian (judgment) peneliti mengenai siapa saja yang pantas (memenuhi persyaratan) untuk dijadikan sampel. Penentuan jumlah responden pada penelitian ini menggunakan derajat kecermatan sebesar $20 \%$ berdasarkan metode Slovin. Penentuan sampel responden untuk penelitian korelasional jumlah sampel minimal untuk memperoleh hasil yang layak adalah 30 responden. Menurut Sugiyono (2008), bahwa ukuran sampel yang layak dalam penelitian adalah antara 30 sampai dengan 500. 
Penilaian terhadap persepsi masyarakat dibagi menjadi 5 tingkatan. Tingkatan yang pertama (1) menunjukkan nilai persepsi masyarakat Sangat Tidak Setuju (STS), kedua (2) menunjukkan nilai persepsi Tidak Setuju (TS), ketiga (3) menunjukkan nilai persepsi Netral (N), keempat (4) menunjukkan nilai persepsi Setuju (S) dan yang kelima (5) menunjukkan nilai persepsi Sangat Setuju (ST). Penilaian terhadap persepsi masyarakat didapatkan dari hasil kuisioner yang disebarkan kepada pengunjung dan masyarakat Pantai Karang Jahe.

\section{b. Parameter Kesesuaian Wisata}

Penentuan stasiun sampling parameter biotik dan abiotik dilakukan secara horizontal dimana dari masingmasing stasiun ditarik garis tegak lurus dari bibir pantai menuju laut. Sampling menggunakan tiga stasiun dimana jarak dari stasiun satu ke stasiun lainnya yaitu sepanjang 20 meter dan jarak stasiun menuju laut yaitu sepanjang 15 meter. Menurut Leonard et al., (2014) penetuan stasiun lokasi penelitian menggunakan metode purposive sampling yaitu metode pengambilan data yang memiliki pertimbangan atau alasan tertentu dengan melihat kondisi di lokasi pengambilan data.

Penentuan stasiun sampling yang digunakan pada penelitian ini dapat dilihat pada gambar 1 berikut ini :

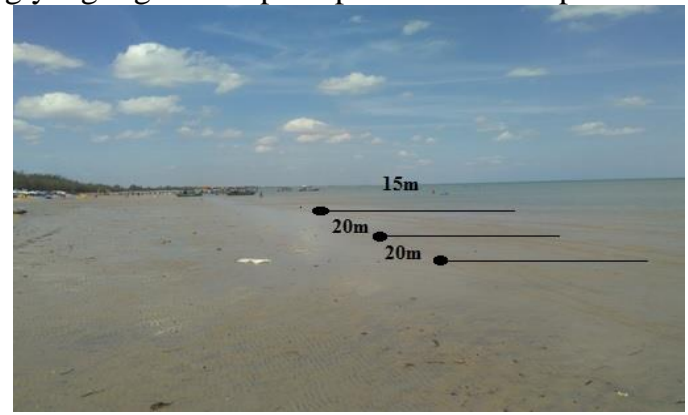

Gambar 1. Penentuan Stasiun

Data diambil dalam dua waktu yaitu pada pagi dan sore hari. Dilihat dari dua waktu tersebut dapat diketahui perbedaan nilai Indeks Kesesuaian Wisata dan kategorinya setiap stasiun pada pagi dan sore hari.

Koordinat stasiun sampling yang digunakan pada penelitian ini yang tersaji pada tabel 1:

Tabel 1. Koordinat Stasiun

\begin{tabular}{cccc}
\hline \multirow{2}{*}{ No. } & \multirow{2}{*}{ Stasiun } & \multicolumn{2}{c}{ Koordinat } \\
\cline { 3 - 4 } & & Latitude & Longitude \\
\hline 1 & Stasiun I & $06^{\circ} 41^{\prime} 10.9^{\prime \prime}$ & $111^{\circ} 24^{\prime} 42.1^{\prime \prime}$ \\
2 & Stasiun II & $06^{\circ} 41^{\prime} 10.7^{\prime \prime}$ & $111^{\circ} 24^{\prime} 42.6^{\prime \prime}$ \\
3 & Stasiun III & $06^{\circ} 41^{\prime} 10.6^{\prime \prime}$ & $111^{\circ} 24^{\prime} 42.7^{\prime \prime}$ \\
\hline
\end{tabular}

Penentuan koordinat stasiun menggunakan alat GPS dan dilakukan pada tiga stasiun. Dimana ketiga stasiun tersebut dapat mewakili secara keseluruhan area yang berada di Pantai Karang Jahe yaitu kedalaman perairan, tipe pantai, lebar pantai, material dasar perairan, kecepatan arus, kemiringan pantai, kecerahan perairan, penutupan lahan pantai, biota berbahaya, ketersediaan air tawar.

2. Data Sekunder

Dalam penelitian ini yang menjadi sumber data sekunder adalah literatur, artikel, jurnal ataupun pengelola masyarakat Pantai Karang Jahe yang berkenaan dengan penelitian yang dilakukan. Adapun data yang dibutuhkan dalam penelitian ini adalah data jumlah pengunjung rekreasi Pantai Karang Jahe selama tahun 2017 dan data monografi desa untuk mengetahui jumlah penduduk Desa unjulharjo.

\section{Analisis Indeks Kesesuaian Wisata}

Analisis dilakukan dengan mempertimbangkan 10 parameter yang memiliki empat klasifikasi penilaian menurut Yulianda (2007) tersaji pada tabel 2:

Tabel 2. Kriteria Kesesuaian Kawasan Untuk Wisata Pantai

\begin{tabular}{ccccccccccc}
\hline No. & Parameter & Bobot & $\begin{array}{c}\text { Kategori } \\
\text { S1 }\end{array}$ & Skor & $\begin{array}{c}\text { Kategori } \\
\text { S2 }\end{array}$ & Skor & $\begin{array}{c}\text { Kategori } \\
\text { S3 }\end{array}$ & Skor & Kategori N & Skor \\
\hline 1 & $\begin{array}{c}\text { Kedalaman } \\
\text { perairan (m) }\end{array}$ & 5 & $0-3$ & 3 & $3-6$ & 2 & $6-10$ & 1 & $>10$ & 0 \\
& Tipe pantai & 5 & $\begin{array}{c}\text { Pasir } \\
\text { putih }\end{array}$ & 3 & $\begin{array}{c}\text { Pasir } \\
\text { putih, } \\
\text { terdapat } \\
\text { sampah }\end{array}$ & 2 & $\begin{array}{c}\text { Pasir } \\
\text { hitam }\end{array}$ & 1 & $\begin{array}{c}\text { Lumpur, } \\
\text { Berbatu, } \\
\text { terjal }\end{array}$ & 0 \\
\hline
\end{tabular}




\begin{tabular}{|c|c|c|c|c|c|c|c|c|c|c|}
\hline 3 & $\begin{array}{l}\text { Lebar pantai } \\
\text { (m) }\end{array}$ & 5 & $>15$ & 3 & $10-15$ & 2 & $3-10$ & 1 & $<3$ & 0 \\
\hline 4 & $\begin{array}{l}\text { Material dasar } \\
\text { perairan }\end{array}$ & 3 & Pasir & 3 & $\begin{array}{l}\text { Karang } \\
\text { berpasir }\end{array}$ & 2 & $\begin{array}{c}\text { Pasir } \\
\text { berlumpur }\end{array}$ & 1 & Lumpur & 0 \\
\hline 5 & $\begin{array}{l}\text { Kecepatan } \\
\text { arus }(\mathrm{m} / \mathrm{s})\end{array}$ & 3 & $0-0,17$ & 3 & $\begin{array}{c}0,17- \\
0,34\end{array}$ & 2 & $\begin{array}{c}0,34- \\
0,51\end{array}$ & 1 & $>0,51$ & 0 \\
\hline 6 & $\begin{array}{l}\text { Kemiringan } \\
\text { pantai }\left(^{\circ}\right)\end{array}$ & 3 & $<10$ & 3 & $10-25$ & 2 & $25-45$ & 1 & $>45$ & 0 \\
\hline 7 & $\begin{array}{l}\text { Kecerahan } \\
\text { perairan }(m)\end{array}$ & 1 & $>80$ & 3 & $50-80$ & 2 & $20-50$ & 1 & $\begin{array}{l}<20 \\
\text { (terdapat } \\
\text { sampah, } \\
\text { kekeruhan } \\
\text { tinggi) }\end{array}$ & 0 \\
\hline 8 & $\begin{array}{l}\text { Penutupan } \\
\text { lahan pantai }\end{array}$ & 1 & $\begin{array}{l}\text { Kelapa, } \\
\text { lahan } \\
\text { terbuka }\end{array}$ & 3 & $\begin{array}{c}\text { Semak } \\
\text { belukar, } \\
\text { rendah, } \\
\text { savana }\end{array}$ & 2 & $\begin{array}{l}\text { Belukar } \\
\text { tinggi }\end{array}$ & 1 & $\begin{array}{c}\text { Hutan } \\
\text { bakau, } \\
\text { pemukiman, } \\
\text { pelabuhan }\end{array}$ & 0 \\
\hline 9 & $\begin{array}{c}\text { Biota } \\
\text { berbahaya }\end{array}$ & 1 & $\begin{array}{l}\text { Tidak } \\
\text { ada }\end{array}$ & 3 & $\begin{array}{c}\text { Bulu } \\
\text { babi/ } 1 \\
\text { spesies }\end{array}$ & 2 & $\begin{array}{c}\text { Bulu } \\
\text { babi/ Ikan } \\
\text { pari/ } 2 \\
\text { spesies }\end{array}$ & 1 & $\begin{array}{c}\text { Bulu babi/ } \\
\text { Ikan pari/ } \\
\text { Hiu/ > } 2 \\
\text { spesies }\end{array}$ & 0 \\
\hline 10 & $\begin{array}{l}\text { Ketersediaan } \\
\text { air tawar (km) }\end{array}$ & 1 & $<0,5$ & 3 & $0,5-1$ & 2 & $1-2$ & 1 & $>2$ & 0 \\
\hline
\end{tabular}

Setelah melakukan penentuan Bobot dan Skor, maka tahap selanjutnya adalah menghiung nilai Indeks Kesesuaian Wisata (IKW) berdasarkan total perkalian Bobot dan Skor semua parameter. Menurut Saputra dan Khodijah (2014), rumus yang digunakan untuk nilai kesesuaian wisata pantai yaitu:

Keterangan:

$$
\mathrm{IKW}=\sum\left\{\frac{\mathrm{Ni}}{\operatorname{Nmax}}\right\} \times 100 \%
$$

IKW = Indeks kesesuaian wisata

$\mathrm{Ni}=$ Nilai parameter ke-i (bobot $\mathrm{x}$ skor)

Nmaks = Nilai maksimum dari suatu kategori wisata

Klasifikasi nilai yang digunakan pada penelitian ini yang tersaji pada Tabel 3:

Table 3. Klasifikasi Nilai

\begin{tabular}{ccc}
\hline No & Klasifikasi & Nilai \\
\hline 1 & Sangat Sesuai (SS) & $83-100 \%$ \\
2 & Sesuai (S) & $50-83 \%$ \\
3 & Sesuai Bersyarat (SB) & $17-50 \%$ \\
4 & Tidak Sesuai (TS) & $<17 \%$ \\
\hline
\end{tabular}

\section{HASIL DAN PEMBAHASAN}

\section{A. Hasil Penelitian}

\section{Gambaran Umum Kabupaten Rembang}

Kabupaten rembang merupakan salah satu kabupaten yang terletak di pesisir Pantura Jawa Tengah yang secara geografis terletak pada $111^{\circ} 00^{`}-111^{\circ} 30^{`} \mathrm{BT}-6^{\circ} 30^{`}-7^{\circ} 06^{\prime} \mathrm{LS}$. Secara administratif, Kabupaten Rembang berbatasan dengan laut Jawa di sebelah utara, Kabupaten Tuban Jawa Timur di sebelah timur, Kabupaten Pati di sebelah barat dan Kabupaten Blora di sebelah selatan. Kabupaten Rembang memiliki wisata alam pantai salah satunya yaitu Pantai Karang Jahe yang menjadi wisata pantai andalan dari Kabupaten Rembang.

\section{Gambaran Umum Pantai Karang Jahe}

Pantai Karang Jahe terletak di Desa Punjulharjo Kecamatan Rembang, Jawa Tengah dengan luas kawasan seluas 393,93 ha. Keunggulan hamparan pasir putih dan ribuan pohon cemara sepanjang $1 \mathrm{~km}$ menjadi daya tarik wisata dari pantai tersebut. Jalan menuju Pantai Karang Jahe sangatlah mudah karena kondisi jalan menuju lokasi sudah beraspal danletak pantai tersebut tidak jauh dari pusat kota, hanya sekitar 7,5 km.

\section{Persepsi Masyarakat Terhadap Potensi dan Perkembangan Wisata Pantai Karang Jahe}

Potensi yang dimiliki obyek wisata Pantai Karang Jahe dikelola secara optimal oleh Badan Pengelola Pantai Karang Jahe. Fasilitas/sarana dan prasarana sangat penting sebagai penunjang kawasan rekreasi. Tingkat kepuasan para 
pengunjung bisa ditentukan dengan kawasan rekreasi dengan fasilitas/ sarana dan prasarana yang baik. Kegiatan wisata yang biasa dilakukan antara lain menikmati pemandangan alam, pasir pantai yang berwarna putih serta berbagai macam rekreasi seperti rekreasi berenang, snorkeling hingga kuliner.

Persepsi pengunjung terhadap potensi wisata terdiri dari kondisi fisik, jenis kegiatan, sarana dan prasarana, aksesibilitas, dan fasilitas di Pantai Karang Jahe. Adapun hasil tersaji pada Tabel 4 :

Tabel 4. Persepsi Pengunjung Terhadap Potensi Wisata Pantai Karang Jahe

\begin{tabular}{|c|c|c|c|c|c|c|c|c|}
\hline No & $\begin{array}{l}\text { Daya Tarik } \\
\text { Wisata }\end{array}$ & STS & TS & $\mathbf{N}$ & $\mathbf{S}$ & SS & $\begin{array}{l}\text { Jumlah } \\
\text { Responden }\end{array}$ & $\begin{array}{c}\text { Presentase } \\
(\%)\end{array}$ \\
\hline 1 & Kondisi fisik pantai & 1 & 1 & 25 & 19 & 4 & 50 & \\
\hline \multirow[t]{7}{*}{2} & Jenis kegiatan & & & & & & & \\
\hline & a. Pemandangan alam & & 2 & 9 & 27 & 12 & 50 & \\
\hline & b. Pasir pantai & & & 14 & 27 & 9 & 50 & \\
\hline & c. Rekreasi berenang & 1 & 2 & 20 & 21 & 6 & 50 & \\
\hline & d. Rekreasi snorkeling & 2 & 6 & 25 & 12 & 5 & 50 & \\
\hline & e. Rekreasi bukit & 2 & 11 & 23 & 9 & 5 & 50 & \\
\hline & f. Kuliner & & 3 & 17 & 22 & 8 & 50 & \\
\hline 3 & Sarana dan prasarana & & 1 & 17 & 22 & 10 & 50 & \\
\hline 4 & Aksesibilitas & & 1 & 23 & 20 & 6 & 50 & \\
\hline \multirow[t]{3}{*}{5} & Fasilitas & 1 & & 22 & 21 & 6 & 50 & \\
\hline & Total & 7 & 27 & 195 & 200 & 71 & & \\
\hline & Presentase & 1.4 & 5.4 & 39 & 40 & 14.2 & & $100 \%$ \\
\hline
\end{tabular}

Keterangan :

STS : Sangat Tidak Setuju, TS: Tidak Setuju, N: Netral, S: Setuju, SS: Sangat Setuju

Persepsi pengunjung terhadap potensi wisata pantai Karang Jahe meliputi 5 parameter yaitu Kondisi fisik pantai, Jenis kegiatan, Sarana dan prasarana, Aksesibilitas dan Fasilitas. Dari data tersebut bisa dilihat bahwa potensi wisata kepada wisatawan mendapat presentase antara lain Sangat Tidak Setuju (STS) sebesar 1.4\%, Tidak Setuju (TS) 5,4\%, Netral (N) 39\%, Setuju (S) 40\% dan Sangat Setuju (SS) 14,2\%.

Persepsi pengunjung terhadap fasilitas / sarana prasarana wisata Pantai Karang Jahemeliputi 8 parameter yaitu loket tiket, tempat area parkir, WC/ toilet kamar mandi, tempat ibadah, tempat duduk, tempat pembuangan sampah, kios/ warung makan, ketersediaan air tawar. Dari data tersebut bisa dilihat bahwa pengunjung puas akan Fasilitas/ Sarana Prasarana yang disediakan dari pihak pengelola Wisata Pantai Karang Jahe. Nilai presentase yang di hasilkan antara lainSangat Tidak Setuju (STS) 0,5\%, Tidak Setuju (ST) $6 \%$, Netral (N) 30\%, Setuju (S) 49,5\% dan Sangat Setuju (SS) $14 \%$.

Persepsi pengunjung terhadap fasilitas / Sarana dan Prasarana yang berada di Pantai Karang Jahe. Adapun hasil tabulasi tersaji pada Tabel 5 :

Tabel 5. Persepsi Pengunjung Terhadap Fasilitas / Sarana Prasarana Wisata Pantai Karang Jahe

\begin{tabular}{|c|c|c|c|c|c|c|c|c|}
\hline No & Fasilitas Pendukung & STS & TS & $\mathbf{N}$ & $\mathbf{S}$ & SS & $\begin{array}{l}\text { Jumlah } \\
\text { Responden }\end{array}$ & $\begin{array}{c}\text { Presentase } \\
(\%)\end{array}$ \\
\hline 1 & Loket tiket & & 3 & 19 & 23 & 5 & 50 & \\
\hline 2 & Tempat area parkir & & 3 & 16 & 25 & 6 & 50 & \\
\hline 3 & $\begin{array}{l}\text { WC/ Toilet kamar } \\
\text { mandi }\end{array}$ & & 5 & 17 & 21 & 7 & 50 & \\
\hline 4 & Tempat ibadah & & 2 & 17 & 23 & 8 & 50 & \\
\hline 5 & Tempat duduk & & 3 & 13 & 26 & 8 & 50 & \\
\hline 6 & $\begin{array}{l}\text { Tempat pembuangan } \\
\text { sampah }\end{array}$ & 2 & 5 & 15 & 24 & 4 & 50 & \\
\hline 7 & Kios/ Warung makan & & 1 & 11 & 32 & 6 & 50 & \\
\hline 8 & Ketersediaan air tawar & & 2 & 12 & 24 & 12 & 50 & \\
\hline & Total & 2 & 24 & 120 & 198 & 56 & & \\
\hline & Presentase & 0.5 & 6 & 30 & 49.5 & 14 & & $100 \%$ \\
\hline
\end{tabular}

Persepsi Pengunjung TerhadapTujuan dan Kegiatan Pengunjung di Pantai Karang Jahe. Adapun hasil tersaji pada Tabel 6 : 
Tabel 6. Persepsi Pengunjung Terhadap Tujuan dan Kegiatan Pengunjung di Pantai Karang Jahe

\begin{tabular}{cccccc|c}
\hline & \multicolumn{5}{c}{ Tujuan Pengunjung } \\
\cline { 2 - 6 } & Fotografi & Berlibur & Penelitian & Lainnya & Total \\
\hline Jumlah & 2 & 43 & & 5 & $\mathbf{5 0}$ \\
\hline Presentase & $4 \%$ & $86 \%$ & $0 \%$ & $10 \%$ & $\mathbf{1 0 0 \%}$ \\
\hline
\end{tabular}

Berdasarkan penilaian persepsipengunjung yang berada di kawasan Pantai Karang Jahe berjumlah 50 orang mendapatkan hasil bahwa $4 \%$ yang berkunjung memilih untuk melakukan fotografi, $86 \%$ pengunjung bertujuan untuk berlibur dan $10 \%$ untuk kegiatan lainnya. Tujuan dari kegiatan lainnya antara lain berenang dan snorkeling.

Persepsi Pengunjung TerhadapTingkat Kepuasan Wisata Pantai Karang Jahe tersaji pada Tabel 7 :

Tabel 7. Persepsi Responden TerhadapTingkat Kepuasan Wisata Pantai Karang Jahe

\begin{tabular}{ccccccccc}
\hline No & $\begin{array}{c}\text { Daya Tarik } \\
\text { Wisata }\end{array}$ & STS & TS & N & S & SS & $\begin{array}{c}\text { Jumlah } \\
\text { Responden }\end{array}$ & $\begin{array}{c}\text { Presentase } \\
(\%)\end{array}$ \\
\hline 1 & $\begin{array}{l}\text { Tingkat kepuasan } \\
\text { pengunjung }\end{array}$ & & 1 & 17 & 20 & 12 & 50 & \\
2 & $\begin{array}{l}\text { Kegiatan untuk } \\
\text { kembali berkunjung }\end{array}$ & 1 & & 17 & 23 & 9 & 50 & \\
\hline & Total & $\mathbf{1}$ & $\mathbf{1}$ & $\mathbf{3 4}$ & $\mathbf{4 3}$ & $\mathbf{2 1}$ & & \\
\hline & Presentase & $\mathbf{1}$ & $\mathbf{1}$ & $\mathbf{3 4}$ & $\mathbf{4 3}$ & $\mathbf{2 1}$ & & $\mathbf{1 0 0 \%}$ \\
\hline
\end{tabular}

Berdasarkan jumlah responden yang diberikan kepada pengunjung yang berada di kawasan Pantai Karang Jahe berjumlah 50 orang didapatkan hasil bahwa tingkat kepuasan dan kembali berkunjung untukSangat Tidak Setuju (STS) sebesar 1\%, Tidak Setuju (TS) 1\%, Netral (N) 34\%, Setuju (S) 43\% dan Sangat Setuju (SS) 21\%. Menurut Priono (2012) dalam Birawa dan Raden (2016) menjelaskan bahwa secara konseptual, ekowisata merupakan suatu konsep pengembangan pariwisata berkelanjutan yang bertujuan untuk mendukung upaya-upaya pelestarian lingkungan (alam dan budaya) dan meningkatkan partisipasi masyarakat dalam pengelolaan sehingga memberi manfaat ekonomi kepada masyarakat setempat.

Persepsi Responden Masyarakat Setempat ada tiga nilai. Nilai pertama adalah tingkat kunjungan, pada penilaian ini mendapatkan jumlah hari kerja sebesar 3.33\%, hari libur $66.67 \%$, akhir pekan $13.33 \%$ dan setiap hari mendapat nilai $16.67 \%$. Nilai kedua adalah fasilitas terbanyak. Pada penilaian ini mendapatkan jumlah nilai ATV $93.33 \%$, perahu $6.67 \%$, mandi bola $0 \%$ dan lainnya $0 \%$. Nilai ketiga yaitu tingkat wisata terbanyak. Pada penilaian ini mendapatkan jumlah nilai wisata snorkeling $6.67 \%$, wisata pantai $76.67 \%$, wisata kuliner $16.66 \%$ dan lainnya $0 \%$.

Persepsi Responden Masyarakat Setempat Terhadap Tingkat Kunjungan, Fasilitas dan Wisata Pantai Terbanyak tersaji pada Tabel 8 :

Tabel 8. Persepsi Responden Masyarakat Setempat Terhadap Tingkat Kunjungan, Fasilitas dan Wisata Pantai Terbanyak

\begin{tabular}{cccccc}
\hline $\begin{array}{c}\text { Kunjungan } \\
\text { terbanyak }\end{array}$ & Hari kerja & Hari libur & Akhir pekan & Setiap hari & Jumlah \\
\cline { 2 - 6 } & 1 & 20 & 4 & 5 & $\mathbf{3 0}$ \\
& $3,33 \%$ & $66,67 \%$ & $13,33 \%$ & $16,67 \%$ & $\mathbf{1 0 0 \%}$ \\
\hline Fasilitas & $\mathbf{A T V}$ & Perahu & Mandi bola & Lainnya & \\
\cline { 2 - 6 } terbanyak & 28 & 2 & 0 & 0 & $\mathbf{3 0}$ \\
& $93,33 \%$ & $6,67 \%$ & $0 \%$ & $0 \%$ & $\mathbf{1 0 0 \%}$ \\
\hline $\begin{array}{c}\text { Wisata } \\
\text { terbanyak }\end{array}$ & $\begin{array}{c}\text { Wisata } \\
\text { snorkling }\end{array}$ & $\begin{array}{c}\text { Wisata } \\
\text { pantai }\end{array}$ & $\begin{array}{c}\text { Wisata } \\
\text { kuliner }\end{array}$ & Lainnya & \\
\cline { 2 - 6 } & 2 & 23 & 5 & 0 & $\mathbf{3 0}$ \\
& $6,67 \%$ & $76,67 \%$ & $16,66 \%$ & $0 \%$ & $\mathbf{1 0 0 \%}$ \\
\hline
\end{tabular}

\section{Nilai Indeks Kesesuaian Wisata (IKW) Pantai Karang Jahe serta Kategorinya}

Hasil dari perhitungan nilai Indeks Kesesuaian Wisata (IKW) Pantai Karang Jahe tersaji pada Tabel 9 dan 10 :

Tabel 9. Nilai Indeks Kesesuaian Wisata (IKW) saat pagi (Surut) Pantai Karang Jahe, Kabupaten Rembang, Jawa Tengah

\begin{tabular}{|c|c|c|c|c|c|c|c|}
\hline \multirow[b]{2}{*}{ No } & \multirow[b]{2}{*}{ Variabel } & \multicolumn{2}{|c|}{ Stasiun 1} & \multicolumn{2}{|c|}{ Stasiun 2} & \multicolumn{2}{|c|}{ Stasiun 3} \\
\hline & & Kategori & $\begin{array}{c}\text { Skor } \\
\text { kategori }\end{array}$ & Kategori & $\begin{array}{c}\text { Skor } \\
\text { kategori }\end{array}$ & Kategori & $\begin{array}{c}\text { Skor } \\
\text { kategori }\end{array}$ \\
\hline 1 & Kedalaman & S1 & 15 & S1 & 15 & S1 & 15 \\
\hline 2 & Tipe pantai & S1 & 15 & S1 & 15 & S1 & 15 \\
\hline 3 & Lebar pantai (m) & S1 & 15 & S1 & 15 & S1 & 15 \\
\hline 4 & $\begin{array}{l}\text { Material dasar } \\
\text { perairan }\end{array}$ & S1 & 9 & S1 & 9 & S1 & 9 \\
\hline
\end{tabular}




\begin{tabular}{|c|c|c|c|c|c|c|c|}
\hline 5 & $\begin{array}{l}\text { Kecepatan arus } \\
\mathrm{m} / \mathrm{s}\end{array}$ & $\mathrm{S} 1$ & 9 & S1 & 9 & S1 & 9 \\
\hline 6 & $\begin{array}{l}\text { Kemiringan } \\
\text { pantai }\left(^{\circ}\right)\end{array}$ & S1 & 9 & S1 & 9 & S1 & 9 \\
\hline 7 & $\begin{array}{l}\text { Kecerahan } \\
\text { perairan }(\mathrm{m})\end{array}$ & S1 & 3 & S3 & 3 & S1 & 3 \\
\hline 8 & $\begin{array}{l}\text { Penutupan lahan } \\
\text { pantai }\end{array}$ & S1 & 3 & $\mathrm{~S} 1$ & 1 & S1 & 3 \\
\hline 9 & Biota berbahaya & S1 & 3 & $\mathrm{~S} 1$ & 3 & $\mathrm{~S} 1$ & 3 \\
\hline 10 & $\begin{array}{l}\text { Ketersediaan air } \\
\text { tawar }(\mathrm{km})\end{array}$ & $\mathrm{S} 1$ & 3 & S1 & 3 & S1 & 3 \\
\hline & & & 84 & & 82 & & 84 \\
\hline
\end{tabular}

Tabel 10. Nilai Indeks Kesesuaian Wisata (IKW) saat sore (Pasang) Pantai Karang Jahe, Kabupaten Rembang, Jawa Tengah

\begin{tabular}{|c|c|c|c|c|c|c|c|}
\hline \multirow[b]{2}{*}{ No } & \multirow[b]{2}{*}{ Variabel } & \multicolumn{2}{|c|}{ Stasiun 1} & \multicolumn{2}{|c|}{ Stasiun 2} & \multicolumn{2}{|c|}{ Stasiun 3} \\
\hline & & Kategori & $\begin{array}{c}\text { Skor } \\
\text { kategori }\end{array}$ & Kategori & $\begin{array}{c}\text { Skor } \\
\text { kategori }\end{array}$ & Kategori & $\begin{array}{c}\text { Skor } \\
\text { kategori }\end{array}$ \\
\hline 1 & Kedalaman & S1 & 15 & S1 & 15 & S1 & 15 \\
\hline 2 & Tipe pantai & S1 & 15 & S1 & 15 & S1 & 15 \\
\hline 3 & Lebar pantai (m) & $\mathrm{S} 1$ & 15 & S1 & 15 & $\mathrm{~S} 1$ & 15 \\
\hline 4 & $\begin{array}{l}\text { Material dasar } \\
\text { perairan }\end{array}$ & S1 & 9 & S1 & 9 & S1 & 9 \\
\hline 5 & $\begin{array}{l}\text { Kecepatan arus } \\
\mathrm{m} / \mathrm{s}\end{array}$ & S1 & 9 & S1 & 9 & S1 & 9 \\
\hline 6 & $\begin{array}{l}\text { Kemiringan } \\
\text { pantai }\left({ }^{\circ}\right)\end{array}$ & S1 & 9 & S1 & 9 & S1 & 9 \\
\hline 7 & $\begin{array}{l}\text { Kecerahan } \\
\text { perairan }(\mathrm{m})\end{array}$ & $\mathrm{N}$ & 0 & $\mathrm{~N}$ & 0 & $\mathrm{~N}$ & 0 \\
\hline 8 & $\begin{array}{l}\text { Penutupan lahan } \\
\text { pantai }\end{array}$ & S1 & 3 & S1 & 3 & S1 & 3 \\
\hline 9 & Biota berbahaya & S1 & 3 & S1 & 3 & S1 & 3 \\
\hline 10 & $\begin{array}{l}\text { Ketersediaan air } \\
\text { tawar }(\mathrm{km})\end{array}$ & S1 & 3 & S1 & 3 & S1 & 3 \\
\hline & & & 81 & & 81 & & 81 \\
\hline
\end{tabular}

\section{B. Pembahasan}

\section{Persepsi Masyarakat Terhadap Potensi dan Perkembangan Wisata Pantai Karang Jahe}

Pantai Karang Jahe merupakan pantai yang memiliki panorama yang sangat indah. Salah satu daya tariknya yaitu pasir putih serta lembut yang membuat para pengunjung senang ketika bermain di pantai. Bukan hanya pasir putihnya, akan tetapi air laut dengan tingkat kecerahan yang sesuai di pantai Karang Jahe ini sangat nyaman jika digunakan untuk mandi, berenang, atau sekedar main air laut.Wisata ini buka mulai pukul 06.00 hingga pukul 18.00 WIB.

Data yang diketahui dari Dinas Kelurahan Punjulharjomenyatakan bahwa beberapa bulan tertentu mengalami kenaikan pada jumlah pengunjung yang signifikan yaitu lebih dari 100.000 pengunjung antara lain pada bulan Januari dengan jumlah 118318 pengunjung, bulan April 104341 pengunjung, bulan Juli 138356 pengunjung dan bulan Desember sebanyak 111943 pengunjung. Perkembangan Pantai Karang Jahe bukan hanya jumlah pengunjung yang meningkat akan tetapi penambahan fasilitas / sarana dan prasarana sebagai penunjang wisatawan juga dikembangkan.

\section{Indeks Kesesuaian Wisata (IKW) Pantai Karang Jahe serta Kategorinya}

Pengukuran yang dilakukan dalam parameter Indeks Kesesuaian Wisata kategori rekreasi hasil yang telah di dapat sebagai berikut :

Hasil pengukuran kedalaman di stasiun I, II dan III saat pagi (surut) dan sore (pasang) berkisar antara 0.18 0.23 meter. Stasiun I saat pagi (surut) sebesar $0.20 \mathrm{~m}$, stasiun II saat pagi (surut) sebesar $0.22 \mathrm{~m}$ dan Stasiun III saat pagi (surut) sebesar $0.23 \mathrm{~m}$ sedangkan Stasiun I saat sore (pasang) sebesar $0.18 \mathrm{~m}$, Stasiun II saat sore (pasang) sebesar $0.22 \mathrm{~m}$ dan Stasiun III saat sore (pasang) sebesar $0.20 \mathrm{~m}$. Nilai dari kedalaman perairan pantai karang jahe menunjukkan bahwa nilai kedalaman perairan tesebut Sangat Sesuai (S1) untuk kegiatan wisata pantai.

Tipe pantai yang telah dilakukan penelitian pada stasiun I, II dan IIIberupa pasir putih. Hal ini dikarena kawasan Pantai Karang Jahe dilakukan perawatan oleh badan pengelola dengan cara pembersihan kotoran yang terbawa 
ke pantai oleh arus yang mengakibatkan pasir terjaga dan masih tetap berwarna putih. Dengan ini tipe pantai mendapatkan nilai kategori sangat sesuai (S1). Hal ini diperkuat oleh Pratesthi et al., (2016) tipe pantai yang sangat sesuai untuk kegiatan wisata pantai berdasarkan jenis substrat/sedimen adalah pantai berpasir.

Pengukuran lebar pantai adalah pengukuran yang diukur dari batas pasang air tertinggi sampai dengan vegetasi terakhir. Pengukuran stasiun I, II dan III pagi (surut) dan sore (pasang) mendapatkan hasil antara 40.6 - 82.5 meter. Stasiun I saat pagi (surut) sebesar $80.5 \mathrm{~m}$, stasiun II saat pagi (surut) sebesar $82.5 \mathrm{~m}$ dan Stasiun III saat pagi (surut) sebesar $81.8 \mathrm{~m}$ sedangkan Stasiun I saat sore (pasang) sebesar $40.6 \mathrm{~m}$, Stasiun II saat sore (pasang) sebesar $41.2 \mathrm{~m}$ dan Stasiun III saat sore (pasang) sebesar $41.5 \mathrm{~m}$. Nilai lebar pantai yang terdapat pada pantai karang jahe bisa dikategorikan semuanya sangat sesuai (S1).

Material dasar perairan yang berada di pantai karang jahe pada saat pengamatan visual rata-rata adalah pasir. Stasiun I, II dan III saat pagi (surut) berupa pasir dan pengamatan stasiun I, II dan III saat sore (pasang) juga berupa pasir. Nilai ini dapat dikategorikan sangat sesuai (S1). Jika dasar perairan berpasir dan lembut bisa dapat disukai anakanak sedangkan jika dasar perairan terdapat pecahan karang atau berlumpur anak-anak merasa kurang nyaman dalam berenang.

Kecepatan arus pada saat pengamat di dua waktu yaitu pagi dan sore hari mendapatkan nilai antara $0.05-0.21$ $\mathrm{m} / \mathrm{s}$. nilai ini dapat dikategorikan sangat sesuai (S1). Berdasarkan hasil pengukuran pada stasiun I, II dan III saat pagi (surut) yaitu $0.11 \mathrm{~m} / \mathrm{s}, 0.05 \mathrm{~m} / \mathrm{s}$ dan $0.07 \mathrm{~m} / \mathrm{s}$. pada saat stasiun I, II dan III saat sore (pasang) yaitu $0.08 \mathrm{~m} / \mathrm{s}, 0.21 \mathrm{~m} / \mathrm{s}$ dan $0.13 \mathrm{~m} / \mathrm{s}$. Kecepatan arus yang lemah sangat baik bagi pengunjung untuk berenang sedangkan jika arus yang sangat kuat bisa membuat pengunjung berbahaya untuk berenang. Hal ini diperkuat oleh Ramadhan et al., (2014). Kecepatan arus juga berhubungan dengan keamanan dan kenyamanan berwisata. Kecepatan arus yang terlalu tinggi akan membahayakan pengunjung, mengingat tidak adanya pembatasan kawasan yang diperbolehkan untuk berenang. Maka parameter ini sangat penting untuk diukur kesesuaiannya.

Kemiringan pantai mempengaruhi keamanan para pengunjung dalam melakukan kegiatan berenang. Pengukuran kemiringan pantai Stasiun I saat pagi (surut) sebesar $0.57^{\circ}$, stasiun II saat pagi (surut) sebesar $1.14^{\circ}$ dan Stasiun III saat pagi (surut) sebesar $2.29^{\circ}$ sedangkan Stasiun I saat sore (pasang) sebesar $1.14^{\circ}$, Stasiun II saat sore (pasang) sebesar $1.72^{\circ}$ dan Stasiun III saat sore (pasang) sebesar $1.72^{\circ}$. Berdasarkan nilai kemiringan pantai karang jahe semua Stasiun dapat dikategorikan sangat sesuai (S1).

Keceraham perairan dimanfaatkan pengunjung untuk berenang dan snorkeling. Pada pengamatan yang dilakukan stasiun I dan III saat pagi (surut) adalah $\infty$ dengan nilai kategori sangat sesuai (S1) dan stasiun II dengan nilai 20 dengan nilai kategori sesuai bersyarat (S3) sedangkan pada pengamatan yang dilakukan pada stasiun I, II dan III saat sore (pasang) adalah 15, 17 dan 15.5 yaitu mendapatkan nilai kategori tisak sesuai (N). Menurut Ardian et al., (2015), kecerahan merupakan kemampuan cahaya matahari yang berpenetrasi masuk keperairan pada kedalaman tertentu. Kecerahan perairan sangat diperlukan bagi kegiatan wisata karena kecerahan perairan yang baik akan memberikan kenyamanan bagi pengunjung tanpa merasa terganggu.

Penutupan lahan, adanya penutupan lahan hal ini bisa dapat memperindah lingkungan serta bermanfaat bagi pengunjung. Penutupan lahan di pantai karang jahe pada Stasiun I, II dan III di saat pagi (surut) dan sore (pasang) yaitu Cemara laut\& Lahan terbuka sehingga penutupan lahan pantai di pantai karang jahe dikategorikan sangat sesuai (S1).

Biota berbahaya sangat penting karena dapat membahayakan pengunjung yang sedang melakukan kegiatan di kawasan wisata. Pengamatan di dua waktu pagi (surut) dan sore (pasang) pada Stasiun I, II dan III sama sekali tidak ditemukan biota yang berbahaya sehingga pantai karang jahe di kategorikan sangat sesuai (S1). Ketersediaan air tawar, jarak antara air tawar pada stasiun I, II dan III pada saat pagi (surut) dan sore (pasang) adalah berjarak $<0.5 \mathrm{~km}$ dengan hal ini ketersediaan air tawar di pantai karang jahe dikategorikan sangat sesuai (S1).

Jarak antara air tawar pada stasiun I, II dan III pada saat pagi (surut) dan sore (pasang) adalah berjarak $<0.5$ $\mathrm{km}$. Dengan hal ini ketersediaan air tawar di pantai karang jahe dikategorikan sangat sesuai (S1). Menurut Hazeri et al., (2016),ketersediaan air tawar/tanah juga merupakan faktor yang utama dalam kegiatan pariwisata pantai.

\section{KESIMPULAN DAN SARAN \\ Kesimpulan}

Potensi pantai karang jahe yaitu terletak pada kondisi fisik yang indah. Pantai yang luas serta pasir putih yang lembut menjadikan daya tarik bagi wisata. Adapun jenis kegiatan yang berada pada pantai karang jahe adalah berenang dan permainan yang sudah disiapkan untuk pengunjung yang disewakan oleh masyarakat setempat. Perkembangan wisata di pantai karang jahe yaitu terletak pada tingkat pertumbuhan jumlah pengunjung serta penambahan fasilitas / sarana dan prasarana, antara lain penambahan wahana permainan, perbaikan jalan dan adanya tukang pijat di area pantai karang jahe dan Indeks Kesesuaian Wisata (IKW) pantai karang jahe terbilang sesuai. Hal ini menjadikan para pengunjung merasa nyaman ketika berekreasi di Pantai Karang Jahe.

\section{Saran}

1. Sebaiknya Daya Tarik bagi wisata lebih dikembangkan lagi seperti meningkatkan sarana permainan wahana air dan wahana darat serta ditambah saung singgah yang luas dan bersih agar para wisatawan lebih banyak kembali datang berkunjung Pantai Karang Jahe. 
2. Sebaiknya Fasilitas / Sarana Prasarana dalam menjaga kebersihanlebih di pentingkan lagi. Hal ini bisa diatasi dengan menambahkan tempat sampah di sekitar kawasan Wisata Pantai Karang Jahe.

\section{UCAPAN TERIMAKASIH}

Mengucapkan terimakasih kepada pihak Dr. Ir. Bambang Sulardiono, M. Si dan Churun Ain, S. Pi, M. Si selaku dosen penguji yang telah memberikan kritik, masukan dan saran perbaikan dalam perbaikan penyusunan skripsi

\section{DAFTAR PUSTAKA}

Ardian., Khodijah dan Linda W, Z. 2015.Kajian Kesesuaian Kawasan Wisata Pantai Dikampung Pasir Panjang Tanjung Siambang Pulau Dompak Kota Tanjung Pinang.Fakultas Ilmu Kelautan dan Perikanan, UMRAH.

Hazeri, G., D, Hartono dan I, Cahyadinata. 2016. Studi Kesesuaian Pantai Laguna Desa Merpas Kecamatan Nasal Kabupaten Kaur Sebagai Daerah Pengembangan Pariwisata dan Konservasi. Jurnal Enggano. 1 (1) : 33-41.

Leonard, J,O., Ibnu, P dan Munasik. 2014. Kesesuaian Perairan Untuk Wisata Selam dan Snorkeling di Pulau Biawak, Kabupaten Indramayu. Jurnal Marine Research. Vol. 3 (3). Hal : 216-225.

Pratesthi P,D,A., Frida, P dan Siti, R. 2016. Studi Kesesuaian Wisata Pantai Nglambor Sebagai Objek Rekreasi Pantai di Kabupaten Gunungkidul. Jurnal Maquares. Vol 5 (4). Hal :433-442.

Priono, Y. 2012. Pengembangan kawasan ekowisata Bukit Tangkiling berbasis masyarakat. Jurnal Perspektif Arsitektur. Vol.7 (1). Hal : 51-67.

Ramadhan, S., Pindi, P dan Zulham A, H. 2014. Analisis Kesesuaian Dan Daya Dukung Kawasan Wisata Pantai Cermin Kabupaten Serdang Bedagai. Jurnal Manajemen Sumberdaya Perairan, USU.

Saputra B, D dan Khodijah. 2014. Kesesuaian Perairan Kawal Sebagai Kawasan Wisata Pantai di Kabupaten Bintan. Jurnal Manajemen Sumberdaya Perairan, UMRAH.

Sugiyono. 2007. Metode Penelitian Pendidikan Pendekatan Kuantitatif, Kualitatif, dan R\&D; Alfabeta, Bandung.

Sugiyono. 2008. Metode Penelitian Kuantitatif, Kualitatif, dan R\&D; Alfabeta, Bandung.

Yulianda F. 2007. Ekowisata Bahari Sebagai Alternatif Pemanfaatan Sumberdaya Pesisir Berbasis Konservasi. Standar Sains Departemen Manajemen Sumberdaya Perairan. Jurnal Fakultas Perikanan dan Ilmu Kelautan. Institut Pertanian Bogor. Bogor. 